\title{
Choice of toothpaste for the elderly: an in vitro study
}

\section{Renata Duarte de SOUZA-RODRIGUES(a) Stella da Silva FERREIRA ${ }^{\text {(a) }}$ Roberta Souza D'ALMEIDA-COUTO(b) Karina Monteleone LACHOWSKI(a) Maria Ângela Pita SOBRAL(a) Márcia Martins MARQUES(a)}

(a) Universidade de São Paulo - USP, School of Dentistry, Department of Restorative Dentistry, São Paulo, SP, Brazil.

(b) Universidade Federal do Pará - UFPA, School of Dentistry, Department of Restorative Dentistry, São Paulo, SP, Brazil.

Declaration of Interests: The authors certify that they have no commercial or associative interest that represents a conflict of interest in connection with the manuscript.

Corresponding Author:

Márcia Martins Marques

E-mail:mmmarques@usp.br

DOI: 10.1590/1807-3107BOR-2015.vol29.0094

Submitted: Jan 06, 2015

Accepted for publication: Apr 07, 2015

Last revision: Jun 24, 2015
Abstract: Hyposalivation and dental root exposure in the elderly are problems that require special oral care. In this context, the characteristics of certain toothpastes are of particular importance. Thus, the aim of this study was to evaluate the cytotoxicity and dentin wear caused by seven different toothpastes. For dentin wear analysis, 40 root dentin specimens were submitted to 20,000 brushing cycles with the different toothpastes and distilled water (control group-CG), using a brushing machine. Dentin surface loss (SL) was measured by contact profilometer. The cytotoxicity of each toothpaste was tested using cultured fibroblasts submitted to a cell-culture-conditioned medium. Fresh medium served as the control. Cell viability was assessed by MTT assay after $24 \mathrm{~h}$ of contact with the conditioned media. The data were analyzed statistically by ANOVA, followed by Tukey's test $(p<0.05)$. The SL of the CG was minimal and significantly lower than that of the Oral B Pro Health $(\mathrm{OBPH})$ group $(\mathrm{p}<0.05)$. All other groups presented SL in between that of the CG and the Oral B Pro Health OBPH group, except for the Sensodyne (SEN) group, which presented SL similar to that of CG $(p=0.05)$. The SEN group presented a percentage of viable cells similar to that of CG: between $60-89 \%$. All the other toothpastes showed high cytotoxicity, with cell viability less than $50 \%$ of the CG. Considering study limitations, we concluded that only one of the seven tested toothpastes exhibited the most desirable toothpaste characteristics for the worldwide growing elderly population (e.g. low cytotoxicity and low-abrasive potential).

Keywords: Dentin; Tooth Wear; Toxicity; Toothpastes.

\section{Introduction}

Toothpastes are the most common daily home oral care product. In fact, tooth brushing with toothpaste is an important oral hygiene habit, with many benefits to dental and gingival health. ${ }^{1}$ The toothpastes must provide maximum cleaning without harming oral tissues; ${ }^{2}$ however, some toothpaste components may cause damage. ${ }^{3}$

Toothpastes are not all identical in composition and should be indicated according to each patient's needs. ${ }^{4}$ The components mostly found in toothpastes are abrasive, surfactant, humectant, gelling and/or binding agents, as well as flavoring, preservative, staining and film agents, sweeteners, fluoride and others. ${ }^{5}$ Differences in the presence and/or concentration of all these components in toothpastes may cause undesirables side effects. Excessive 
fluoride may be dangerous to young people. ${ }^{67} \mathrm{On}$ the other hand, excessive abrasives or potentially cytotoxic components are harmful to the elderly population.

Today, the elderly population retain their teeth in their mouth longer. Moreover, physiological or pathological alterations (e.g. caries, non-carious lesions, enamel wear, periodontal treatment, etc.) cause the dentin to be exposed, ${ }^{8}$ after which it is subjected to brushing with toothpastes. Knowing that toothpastes may not only remove the oral biofilm, but also cause wear of the exposed dentin, ${ }^{9}$ greater attention should be given to the prescription of toothpastes for this population, in order to avoid greater wear of this exposed substrate. Furthermore, this population generally presents levels of xerostomia, caused by the use of medications; in this scenario, toothpaste may also cause irritation, allergic reaction, mucosal desquamation, ulceration and dermatitis. ${ }^{5}$

Based on the above considerations, low levels of abrasivity and cytotoxicity are desirable characteristics of toothpastes for the elderly population. Thus, the aim of this study was to analyze both the abrasivity and the cytotoxicity of different brands of toothpaste.

\section{Methodology}

This study was approved by the Local Research Ethics Committee (Protocol 151/11-FR 470424).

\section{Toothpastes}

Table shows the commercially available toothpastes selected for the study. Each toothpaste variety in this in vitro study was submitted to physical (dentin wear susceptibility) and biological (cytotoxicity) analyses.

\section{pH measurement}

The $\mathrm{pH}$ of each toothpaste was measured in a suspension composed of one part toothpaste mass to three parts water mass, according to ISO $11609 .{ }^{10}$ The $\mathrm{pH}$ of each suspension was determined within 10 minutes, using a calibrated $\mathrm{pH}$-meter and an electrode assembly (Accumet 13-620-530; Fisher Scientific, Pittsburgh, USA).

\section{Dentin wear analysis model}

\section{Specimen preparation}

Forty specimens of root dentin $(5 \times 5 \mathrm{~mm})$ were obtained from bovine incisors to analyze the abrasive potential of all toothpastes. These specimens were embedded in acrylic resin, and then grounded flat with water-cooled abrasive discs (500-, 1200-, 2400and $4000-\mathrm{Al}_{2} \mathrm{O}_{3}$ papers, Buehler, USA) and polished with felt discs and diamond paste $(1 \mu \mathrm{m}$ Buehler). Adhesive tape strips were placed on the polished surface of each specimen, leaving an exposed window of $4 \times 1 \mathrm{~mm}$. The root dentin specimens $(\mathrm{n}=5)$ were then randomly submitted to brushing with the 7 toothpastes or with distilled water (control).

\section{Experimental protocol}

The specimens were mounted on a brushing machine (MSEt - ELQUIP, São Carlos, Brazil) to simulate the dental abrasion in vitro, and submitted to 20,000 brushing cycles with a load of $200 \mathrm{~g}$, using soft-bristle brushes (Sorriso ${ }^{\circledast}$ Kolynos Master, Colgate-Palmolive Company, São Paulo, Brazil). The internal temperature of the machine during all cycles was maintained nearly $37 \pm 1^{\circ} \mathrm{C}$. A slurry with

Table. Toothpastes, their respective manufacturers and their main components.

\begin{tabular}{|c|c|c|}
\hline Toothpaste (group) & Manufacturer & Main components \\
\hline Oral B 123 (OB123) & Procter \& Gamble, Rio de Janeiro, RJ, Brazil & Sodium lauryl sulfate, hydrated silica \\
\hline Oral B Pro-Health (OBPH) & Procter \& Gamble, Rio de Janeiro, RJ, Brazil & Sodium lauryl sulfate, silica \\
\hline Freshup (FRUP) & Boniquet do Brasil, São Paulo, SP, Brazil & Sodium lauryl sulfate, calcium carbonate, sodium silicate \\
\hline Sorriso Super Refreshing ( SOR) & Colgate-Palmolive Company, São Paulo, SP, Brazil & $\begin{array}{c}\text { Sodium lauryl sulfate, calcium carbonate, sodium bicarbonate, } \\
\text { sodium silicate }\end{array}$ \\
\hline Colgate Triple Action (CTA) & Colgate-Palmolive Company, São Paulo, SP, Brazil & $\begin{array}{c}\text { Sodium lauryl sulfate, calcium carbonate, sodium bicarbonate, } \\
\text { sodium silicate }\end{array}$ \\
\hline Colgate Total 12 (CT12) & Colgate-Palmolive Company, São Paulo, SP, Brazil & Sodium lauryl sulfate, hydrated silica \\
\hline Sensodyne Original (SEN) & GlaxoSmithKline, Rio de Janeiro, RJ, Brazil & Sodium lauryl sulfate, amorphous silica \\
\hline
\end{tabular}


distilled water was prepared for each toothpaste, in a proportion of 1 part toothpaste to 2 parts distilled water, immediately before using. ${ }^{11}$ The slurry was then added to wells positioned in the brushing machine, and was discharged onto the dentin surface at one-minute intervals during the test run. Each experimental group was tested individually, to keep the different toothpastes from mixing together.

\section{Dentin wear measurement}

The dentin wear measurements were performed by a single, well-trained examiner blinded to the groups. After completing the experimental protocol, the tape strips were removed and the surface profile of each specimen was measured using a contact surface profilometer (Legex 9106, Mitutoyo, Japan). The analyses were made at three different points along the dentin surface of each specimen, crossing the two reference surfaces covered with the adhesive tape, as well as the test area exposed to the abrasion model. The wear value of each specimen was the mean result of these three measurements.

\section{Cytotoxic analysis model}

\section{Cell culture}

Human gingival fibroblasts (FMM1 cell line ${ }^{12}$ ) were used. The cells were cultured in high glucose Dulbecco's modified Eagle Medium (DMEM, LGC Biotecnologia, Cotia, Brazil), supplemented with 10\% fetal bovine serum (FBS, Cultilab, Campinas, Brazil) and $1 \%$ antibiotic-antimycotic solution (Sigma Aldrich, St. Louis, USA). The cells were maintained in an incubator at $37^{\circ} \mathrm{C}$, in a humid atmosphere containing $5 \% \mathrm{CO}_{2}$ and $95 \%$ air. The cell growth was monitored daily under a phase contrast microscope; the culture medium was changed every other day. The cells were harvested and plated into 24-well culture plates to perform the experiments.

\section{Conditioned medium}

The conditioned medium (e.g. medium containing substances leached or dissolved from each toothpaste) was obtained as recommended by the American Society for Testing Material. ${ }^{13}$ In brief, test tubes containing the toothpastes were filled with DMEM (LGC Biotecnologia, Cotia, Brazil). Conditioning was carried out for $1 \mathrm{~h}$, at $37^{\circ} \mathrm{C}$, using $0.2 \mathrm{~g}$ of each toothpaste per milliliter of fresh medium.

\section{Experimental protocol}

The experiments were conducted as follows: the cells were plated $\left(2 \times 10^{3}\right.$ cells/well) in 24-well culture plates and maintained in a humidified chamber at $37^{\circ} \mathrm{C}$. Twenty-four hours later the culture medium was exchanged for the experimental conditioned medium, which was kept in contact with the cells for $5 \mathrm{~min}$, in order to simulate the brushing procedure time. The control group received a fresh culture medium. Then, the conditioned medium was exchanged for fresh medium and the cultures were incubated in a humidified chamber at $37^{\circ} \mathrm{C}$. All the experimental groups were tested in triplicate.

\section{Cell viability assay}

Twenty-four hours after exposure of the cells to the conditioned medium, the cell viabilities of all toothpastes and control were measured. This analysis was based on cell mitochondrial activity measured by the MTT-based cytotoxicity assay. ${ }^{14}$ This test measures the ability of mitochondrial enzymes produced by metabolically active cells to reduce 3-(bromide, 4,5-dimethylthiazol-2yl)-2,5-diphenyltetrazolium (MTT; Invitrogen, Eugene, OR, USA) molecules to an insoluble salt of formazan, detected by absorbance at $562 \mathrm{~nm}$ using a spectrophotometer (Amersham Biosciences, Biochrom Ltd., Cambridge, England). According to Freshney, ${ }_{1}^{15}$ this assay determines the cell viability indirectly. Thus, the absorbance data of the control group grown in ideal cell culture conditions indicates the maximum cell number in one well. The comparison of these data with those of the experimental groups indirectly indicates the number of viable cells in the experimental wells. Therefore, the mean optical density of the control group was considered as having $100 \%$ cell viability. The toothpastes were considered non-cytotoxic when the mean cell viability was higher than $90 \%$, low-cytotoxic when the mean cell viability was between $60-89 \%$, and highly cytotoxic when the cell viability was less than $59 \%$. 


\section{Statistical analysis}

The data of both experiments were compared by one-way ANOVA, complemented with the Tukey test. The level of significance was set at $5 \%(p<0.05)$. BioEstat software 5.0 was used to perform the analysis.

\section{Results}

\section{Toothpaste $\mathrm{pH}$}

The $\mathrm{pH}$ of all toothpastes ranged from 6.23 to 9.79, in that: SOR - 9.79, CTA - 9.54, OB123 - 8.90, FRUP - 8.73, SEN - 7.62, CT12 - 7.28 and OBPH - 6.23.

\section{Dentin wear analysis}

The dentin wear measured as surface loss in all the experimental groups is graphically represented in Figure 1. The surface loss caused by distilled water was minimal and significantly less than that of $\mathrm{OBPH}$ (Oral B Pro-Health; $\mathrm{p}<0.05$ ). All of the other groups presented surface loss in between that caused by distilled water and that of OBPHG, except for SEN. This toothpaste presented a surface loss similar to that caused by distilled water $(p=0.05)$.

\section{Cytotoxic analysis}

Figure 2 illustrates the percentages of cell viability in all the experimental groups 24 hours after contact with the culture medium conditioned by the toothpastes. The mean optical density of the control group was considered $100 \%$. The SEN group presented a percentage of viable cells similar to that of control group, which was in the range of $60-89 \%$, considered as low-cytotoxic. The other experimental groups showed high cytotoxicity, with cell viabilities lower than $50 \%$ of the control group.

\section{Discussion}

Oral hygiene procedures, along with the adoption of preventive measures, have enabled longer maintenance of the teeth in the oral cavity. Bearing this in mind, the oral care of the world's growing elderly population is a concern. These individuals generally have several tooth surfaces with exposed dentine, which risk being abraded by toothpastes containing abrasives. Moreover, because it is not uncommon for elderly people to take several medications, they generally present different levels of xerostomia, causing cytotoxic components of the toothpastes to easily damage the oral mucosa. Therefore, it is very important that the elderly be prescribed toothpastes that are non-cytotoxic and less abrasive, and that contain a high concentration of fluoride. These concerns led us to investigate the physical (dentin wear) as well as the biological (cytotoxicity) effects of wide-ranging brands and prices of toothpaste used in Brazil and other countries. This study showed that most of the toothpastes analyzed presented not only cytotoxic effects on cultured fibroblasts, but also different levels of abrasive activity.

Bovine dentin specimens were used to analyze the physical effects of the toothpastes. In fact, studies

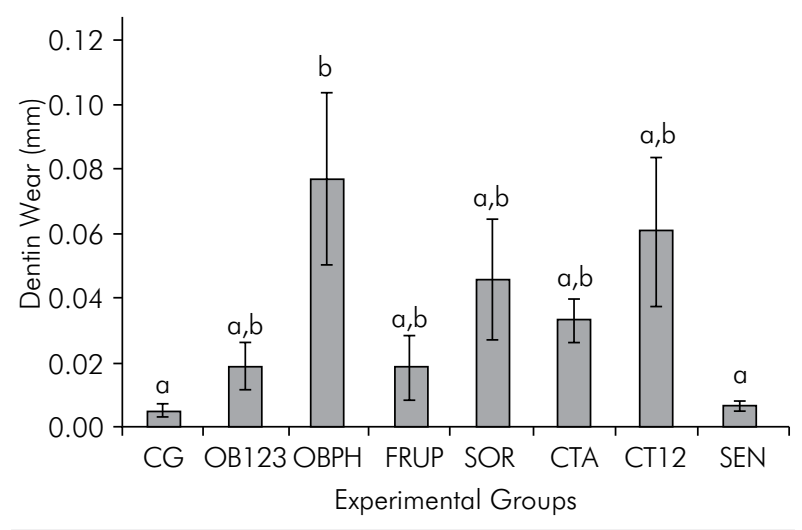

Figure 1. Mean values ( \pm standard error of the mean) of surface loss $(\mathrm{mm})$. Different letters indicate significant differences $(p \leq 0.05)$.

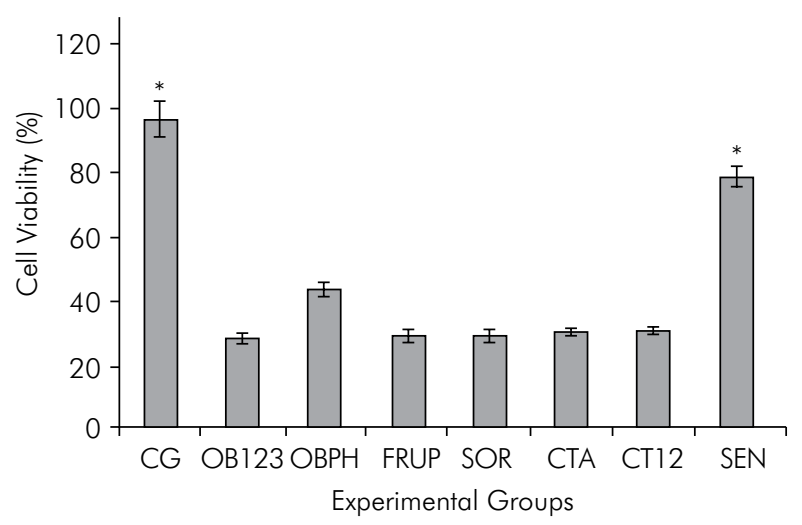

* Significantly higher than all the other groups ( $p \leq 0.05$ ).

Figure 2. Cell viabilities ( $\% \pm$ standard error of the mean) in the experimental time period of 24 hours. 
have shown that bovine dentin can be used as a substitute substrate for human dentin. . $^{16,17}$

The effect of the toothpastes on dentin integrity was evaluated by using profilometry, which allows surface loss to be analyzed and quantified. This method is recommended by ISO 11609 and has been extensively used for other abrasion studies..$^{18,19,20}$ There were surface losses at different levels, caused by the different toothpastes; however, this finding suggests that the losses were not due to erosion, because the $\mathrm{pH}$ of the detergents was above neutral.

Oral B Pro-Health $(\mathrm{OBPH})$ was considered the most abrasive toothpaste among all the products analyzed. On the other hand, it was observed that only Sensodyne (SEN) presented a minimal abrasive effect on bovine dentin, an effect similar to that of tooth brushing with distilled water. Previous studies demonstrated that toothpastes contain a number of ingredients that can remove not only the oral biofilm but also the superficial dentin tissue. Among these components, abrasives and detergents are cited more often. ${ }^{3,8}$ Abrasives are important for removing deposits on the teeth. ${ }^{7}$ Derivatives of silica, like hydrated silica or amorphous silica, calcium carbonate, sodium bicarbonate, dicalcium phosphate dihydrate, calcium pyrophosphate and alumina are abrasives found in toothpastes. ${ }^{20,21}$ According to the manufactures of the toothpastes evaluated in the present study, there were differences among these toothpastes in regard to the formulation of abrasives. Whereas OBPH contains an association of two abrasives (e.g. silica and hydrated silica), the SEN group presented only one abrasive (e.g. amorphous silica) in its composition. The association of abrasives in OBPH could implicate the abrasive potential of this toothpaste, since the surface loss caused by OBPH was significantly higher than that of SEN. On the other hand, all of the other toothpastes presented an intermediary abrasive potential between OBPH and SEN, and these other toothpastes presented just one type of abrasive in their composition. Therefore, other factors must be responsible for the abrasive potential of the toothpastes studied, since the association of abrasives alone cannot explain our findings. The abrasiveness of toothpaste depends not only on the chemical compound but also on the amount of the substance, particle size, shape, surface, structure of the particle, chemical interaction with other ingredients and the $\mathrm{pH}$ of the product. ${ }^{22,23}$ However, this information is not made available, thereby making it difficult to attribute the abrasive potential of the toothpastes to any specific abrasive agent in their formulation.

Detergents have also been involved in the abrasive potential of toothpastes. Moore and Addy ${ }^{3}$ showed that detergents can modulate the effect of abrasives in dentin wear in a way that may reflect the rheological properties of the mixture. The only detergent present in all toothpaste formulations studied was sodium lauryl sulphate, which is an anionic detergent. According to these authors, this class of detergent is the most aggressive in terms of abrasiveness; however, because all the toothpastes had this detergent, sodium lauryl sulphate could not be singled out as solely responsible for the differences in the surface losses observed. Therefore, the hypothesis that potential for dentin wear resulted from the association of this detergent with other components of the toothpastes seemed more feasible.

In performing the initial analysis to determine the biological influence of the toothpastes on oral soft tissues, it was decided that the effect of these materials on the viability of oral gingival fibroblasts should be studied. In fact, cell culture studies often supply information about cellular response to the products being tested. Although the cell culture findings cannot be directly applied to in vivo tissues, the results obtained in vitro can be used as the basis for other studies, such as experimental animal models.

Among the seven toothpastes evaluated, only one (SEN) proved low-cytotoxic, whereas the others were classified as highly cytotoxic, considering that the cell viabilities were lower than $50 \%$. This decrease in cell viability can be attributed to the effect of components of the toothpastes, whether alone or combined. In fact, some studies have already demonstrated that these toothpaste components were responsible for cultured cell death. ${ }^{24,25}$ The main component associated with the adverse effects of the toothpastes studied was more likely to be the sodium lauryl sulphate present in all formulations, because this anionic detergent can cause adverse effects on cells, as a consequence of its ionic properties, responsible for initiating the process of cell 
death. ${ }^{26}$ However, all the toothpastes studied presented this detergent in their formulations, and only SEN proved to be biocompatible. This toothpaste probably presents a lower concentration of this detergent. In fact, it produces less foam, which could be attributed to the low amount of detergent in its formulation. Corroborating this hypothesis, Neppelberg et al. ${ }^{26}$ have already shown a direct correlation between sodium lauryl sulphate concentration and cell death in epithelial cells.

Another component that has been associated with the cytotoxicity of oral mucosa is triclosan, an active ingredient used in toothpastes, which presents antibacterial activity and an anti-plaque effect. ${ }^{5}$ In the toothpastes studied, only CT12 and SEN presented this antiseptic in their formulation. These toothpastes presented a significantly different cytotoxic effect; SEN was biocompatible, whereas CT12 was highly cytotoxic. An in vitro study that evaluated the toxicology of triclosan at the cellular level showed that this ingredient damages the integrity of the plasma membrane, and apparently induces cell death by apoptosis. ${ }^{27}$ Moreover, the abovementioned authors observed that the combination of triclosan with $\mathrm{NaF}$ or $\mathrm{Zn}$ citrate increased the cytotoxic potential of the triclosan. ${ }^{27}$ This can explain the high toxicity of the CT12 group, because the combination of triclosan and $\mathrm{NaF}$ was present only in this toothpaste.

\section{References}

1. Addy M, Hunter ML. Can tooth brushing damage your health?. Effects on oral and dental tissues. Int DentJ. 2003;53:Suppl3:177-86.

2. Vincentini BC, Braga SRM, Sobral MAP. The measurement in vitro of dentine abrasion by toothpastes. Int Dent J. 2007 Oct;57(5):314-8.

3. Moore C, Addy M. Wear of dentine in vitro by toothpaste abrasives and detergents alone and combined. J Clin Periodontol. 2005 Dec;32(12):1242-6.

4. Cury JA, Tenuta LM. Evidence-based recommendation on toothpaste use. Braz Oral Res. 2014;28 Spec:1-7.

5. Davies R, Scully C, Preston AJ. Dentifrices-an update. Med Oral Patol Oral Cir Bucal. 2010 Nov;15(6):e976-82.

6. Barbier O, Arreola-Mendoza L, Del Razo LM. Molecular mechanisms of fluoride toxicity. Chem Biol Interact. 2010 Nov;188(2):319-33.

7. Tenuta LM, Cury JA. Fluoride: its role in dentistry. Braz Oral Res. 2010;24 Suppl 1:9-17.
The results of the present study support the concerns about the use of any kind of toothpaste by the elderly population. The present study showed that there are wide-ranging brands and prices of toothpastes, some of which may be cytotoxic and cause different levels of dentine wear. Differences in the formulations of these toothpastes may be responsible for these effects; however, the manufactures do not inform the composition of toothpastes in detail. This makes it difficult to indicate the most appropriate toothpaste for each clinical case. In fact, for children, the major concern resides more in the amount of toothpaste than in its composition. Toothpastes for children have fluoride in their composition and dentists should recommend only a small amount of these toothpastes, because an excessive amount of fluoride is known to be highly harmful to health. ${ }^{6,78}$ However, in dealing with the elderly, the knowledge of the physical and biological effects of toothpastes is of relevance for most correctly indicating the least harmful toothpaste.

Considering thelimitations of this study, we concluded that only one (SEN) of the seven toothpastes tested exhibited the most desirable toothpaste characteristics for the worldwide growing elderly population (e.g. low-cytotoxicity and low abrasive potential). However, more studies must be conducted to confirm the results of this study, including clinical trials.

8. Pearce NX, Addy M, Newcombe RG. Dentine hypersensitivity: a clinical trial to compare 2 strontium densensitizing toothpastes with a conventional fluoride toothpaste. J Periodontol. 1994 Feb;65(2):113-9.

9. West N, Addy M, Hughes J. Dentine hypersensitivity: the effects of brushing desensitizing toothpastes, their solid and liquid phases, and detergents on dentine and acrylic: studies in vitro. J Oral Rehabil. 1998 Dec;25(12):885-95.

10. International Organization for Standardization 11609: dentistry-dentifrice-requirements, tests and marking. Geneva: ISO; 2010.

11. Palazon MT, Scaramucci T, Aranha AC, Prates RA, Lachowski KM, Hanashiro FS, Youssef MN. Immediate and short-term effects of in-office desensitizing treatments for dentinal tubule occlusion. Photomed Laser Surg. 2013 Jun;31(6):274-82. 
12. Ruano R, Jaeger RG, Jaeger MM. Effect of a ceramic and a non-ceramic hydroxyapatite on cell growth and procollagen synthesis of cultured human gingival fibroblasts. J Periodontol. 2000 Apr;71(4):540-5.

13. American Society for Testing and Materials Annual Book of ASTM Standards: Medical Devices. West Conshohocken (USA): ASTM; 1992.

14. Mosmann T. Rapid colorimetric assay for cellular growth and survival: application to proliferation and cytotoxicity assays. J Immunol Methods. 1983 Dec;65(1-2):55-63.

15. Freshney RI. Culture of Animal Cells: A Manual of Basic Technique and Specialized Applications. 6th ed. New Jersey: Wiley-Blackwell; 2010. 1170 p.

16. Camargo MA, Marques MM, Cara AA. Morphological analysis of human and bovine dentine by scanning electron microscope investigation. Arch Oral Biol. 2008 Feb;53(2):105-8.

17. Wegehaupt FJ, Widmer R, Attin T. Is bovine dentine an appropriate substitute in abrasion studies? Clin Oral Invest. 2010 Apr;14(2):201-5.

18. Giles A, Claydon NC, Addy M, Hughes N, Sufi F, West NX. Clinical in situ study investigating abrasive effects of two commercially available toothpastes. J Oral Rehabil. 2009 Jul;36(7):498-507.

19. Liljeborg A, Tellefsen G, Johannsen G. The use of a profilometer for both quantitative and qualitative measurements of toothpaste abrasivity. Int J Dent Hyg. 2010 Aug;8(3):237-43.
20. Johannsen G, Tellefsen G, Johannsen A, Liljeborg A. The importance of measuring toothpaste abrasivity in both a quantitative and qualitative way. Acta Odontol Scand. 2013 May-Jul;71(3-4):508-17.

21. Franzò D, Philpotts CJ, Cox TF, Joiner A. The effect of toothpaste concentration on enamel and dentine wear in vitro. J Dent. 2010 Dec;38(12):974-9.

22. Forward GC. Role of toothpastes in the cleaning of teeth. Int Dent J. 1991 Jun;41(3):164-70.

23. Hilgenberg SP, Pinto SCS, Farago PV, Santos FA, Wambier DS. Physical-chemical characteristics of whitening toothpaste and evaluation of its effects on enamel roughness. Braz Oral Res. 2011 Jul-Aug;25(4):288-94.

24. Norton JN, Rylander LA, Richards JL. In vitro oral mucosa irritation testing with human cell cultures. Toxicol In Vitro. 1995 Feb;9(1):67-74.

25. Tsutsui T, Tanaka Y, Ushimura A, Ide T, Matsumura M, Barrett JC. In Vitro cytotoxicity of diverse preparations used in dental practice to human gingival keratinocytes. Toxicol In Vitro. 1997 Aug;11(4):393-8.

26. Neppelberg E, Costea DE, Vintermyr OK, Johannessen AC. Dual effects of sodium lauryl sulphate on human oral epithelial structure. Exp Dermatol. 2007 Jul;16(7):574-9.

27. Zuckerbraun HL, Babich H, May RJ, Sinensky MC. Triclosan: cytotoxicity, mode of action, and induction of apoptosis in human gingival cells in vitro. Eur J Oral Sci. 1998 Apr; 106:628-36. 